\title{
Investigation on the Oral Health Knowledge, Attitudes and Behavior Among Pregnant Women in China and Analysis of the Influencing Factors
}

\author{
Liu Yun, Sun Jin, Wu Min* and Luo Quan \\ Stomatology Health Care Center, Affiliated Shenzhen Maternity \& Child Healthcare Hospital of the Southern Medical University, China
}

Submission: June 25, 2020; Published: July 02, 2020

*Corresponding author: Wu Min, Stomatology Health Care Center, Affiliated Shenzhen Maternity \& Child Healthcare Hospital of the Southern Medical University, China

\begin{abstract}
Abstarct
Objective: To understand the degree of grasp of oral health knowledge and related attitudes and attitudes of Chinese pregnant women Understand Chinese women's knowledge of oral health and their related attitudes and behaviors during pregnancy.

Methods: 304 pregnant women with 10 to 12 weeks of obstetrical physical examination were included in the survey, and they voluntarily received a questionnaire survey from the Center for Stomatological Disease Control. The questionnaire was completed in a face-to-face questionand-answer manner.

Result: $38.81 \%$ of pregnant women did not understand the need for oral examination before pregnancy, 49.34\% of pregnant women did not understand that oral diseases are prone to occur after pregnancy, only $40.13 \%$ of pregnant women know that oral diseases during pregnancy will affect fetal health, $47.04 \%$ of pregnant women think Oral treatment is not allowed during pregnancy. At least more than a quarter of pregnant women have a negative attitude towards oral health. Only $13.49 \%$ of pregnant women spend more than 3 minutes each time brushing their teeth, $56.25 \%$ of pregnant women never use dental floss, and $58.88 \%$ of pregnant women have never had oral examinations since their planned pregnancy. Pregnancy, education and family income all affect pregnant women's oral health knowledge and behavior. The higher the education level of pregnant women and the higher the family income, the more accurate oral health knowledge they have and the more correct oral Health care behavior.
\end{abstract}

Conclusion: Chinese pregnant women have obvious deficiencies in oral health knowledge and practice, especially in oral health behaviors that need to be improved and improved. Strengthening oral health education, education and family income can help improve pregnant women's oral health knowledge and behavior Cognition.

Keywords: Pregnant women; Oral health; Knowing and doing; Investigation

\section{Introduction}

Pregnancy is a special and complex physiological process. Women's dietary habits and structure have changed significantly after pregnancy, such as a significant increase in eating frequency, preference for sweet and sour foods, pregnancy reactions can cause vomiting, hormone levels during pregnancy, immune status and Changes in factors such as emotions can have an adverse effect on oral health, which can easily lead to oral diseases [1-3]. Studies have shown that gingivitis during pregnancy is the most common disease in periodontal disease during pregnancy, with an incidence of between 30\% and 100\% [4]. In 1996, Offenbacher et al. [5] found that periodontitis was a risk factor for preterm and low birth weight infants in pregnancy outcomes through case-con trol studies, with OR values of 7.9 and 7.5 , respectively. It was first proposed that the important source of infection during pregnancy may be periodontal infection. Relevant guidelines and scholars all over the world recommend oral care as a part of routine examination and health care during pregnancy $[6,7]$. In order to fully understand the knowledge of oral health knowledge, related attitudes and behaviors of pregnant women, this study selected pregnant women in the obstetric outpatient clinic of the Shenzhen Maternal and Child Health Hospital in Guangdong Province, China to conduct a related investigation and analysis, with a view to the oral health during pregnancy Provide references for education and practical guidance. 


\section{Materials and Methods}

\section{Respondents}

Women who are pregnant during June 2018 to November 2019 will voluntarily receive a questionnaire survey from the Oral Disease Control Center during the 10th to 12th week of pregnancy when establishing an obstetric examination file in the Obstetrics Clinic of the Shenzhen Maternal and Child Health Hospital, Guangdong Province, China.

Inclusion criteria: (1) No systemic diseases; (2) No smoking, alcoholism and other bad habits; (3) No antibiotics or vasodilator drugs within 3 months; (4) Informed consent, voluntary cooperation in questionnaire survey And sign the informed consent.

Exclusion criteria: (1) being undergoing orthodontic treatment; (2) having pathological pregnancy, pregnancy comorbidities or complications; (3) history of miscarriage or stillbirth of 2 or more times. This study was approved by the Medical Ethics Committee of Shenzhen Maternal and Child Health Hospital.

\section{Questionnaire Survey Method}

With reference to the fifth edition of "Basic Methods of Oral Health Survey" published by the World Health Organization (WHO) [8], the "Oral Survey Questionnaire for Women in Pregnancy" was designed by ourselves. The questionnaire was fixed by two dental specialists. During the investigation, the questionnaire was used to complete the questionnaire face-to-face with the pregnant women under investigation to ensure the authenticity of the survey and avoid omission of answers. During the investigation, the questionnaire can give a brief explanation of the relevant questions, and no guidance hints can be given.

\section{Questionnaire Survey Content}

The questionnaire survey mainly includes four major contents (1) Basic information, such as age, pregnancy time, education level, Family income; (2) Knowledge of oral health knowledge, such as whether oral examination is needed before pregnancy, whether oral diseases and related diseases are prone to occur after pregnancy, whether oral diseases during pregnancy have an impact on fetal health, and whether it is possible during pregnancy Oral treatment; (3) Investigation of oral health-related attitudes, such as whether they are willing to participate in oral health education activities during pregnancy, whether they have oral problems during pregnancy, and the main factors affecting medical treatment; (4) oral health-related behavior surveys, such as daily brushing The number of times, the time of each brushing, the use of dental floss, whether or not you have had oral examinations from the planned pregnancy to the present.

\section{Statistical Methods}

Use Epi Data 3.02 software to build the database, and use the double entry method to enter the data to ensure the accuracy of the entered data. SPSS 25.0 software was used for statistical analysis of the data. The statistical methods used were chi-square test and Fisher's exact test. The two-sided test with $\mathrm{P}<0.05$ was considered statistically significant.

\section{Results}

\section{Basic Situation a Total of 304 Pregnant Women Were Included in the Survey}

The age ranged from 22 to 45 years, with an average age of 30.78 years. See Table 1 for details. In the education level, low education means graduation from elementary school or junior high school, middle school education means graduation from secondary school or high school, and high school education means graduation from college or above. Among family incomes, low income refers to less than 5,000 yuan/month, middle income refers to 5,000-19999 yuan/month, and high income refers to more than 20,000 yuan/month.

Table 1: Basic information of 304 pregnant women.

\begin{tabular}{|c|c|c|}
\hline Basic Situation & N & \% \\
\hline Age & & \\
\hline$<35$ years old & 257 & 84.54 \\
\hline$\geq 35$ years old & 47 & 15.46 \\
\hline Education Level & & \\
\hline low & 40 & 13.16 \\
\hline in & 89 & 29.27 \\
\hline high & 175 & 57.57 \\
\hline Pregnancy & & \\
\hline For the first time & 186 & 61.18 \\
\hline Non-first & 118 & 38.82 \\
\hline Household Income & & \\
\hline low & 46 & 15.13 \\
\hline in & 176 & 57.9 \\
\hline high & 82 & 26.97 \\
\hline
\end{tabular}

Investigation on the Knowledge of Oral Health Knowledge

The knowledge of oral health knowledge is shown in Table 2. In addition, pregnant women believe that among the oral diseases that are easy to occur after pregnancy, gum bleeding accounts for the highest proportion, $33.33 \%$, followed by dental caries, $17.95 \%$, loose teeth $10.26 \%$, and wisdom teeth inflammation $7.69 \%$. See Table 3 for the analysis of oral health knowledge. There is no statistical difference in the level of oral health knowledge among pregnant women of different ages. Whether non-first-pregnancy pregnant women need oral examination before pregnancy, whether oral diseases are prone to occur during pregnancy, and whether oral treatment can be done during pregnancy are more accurate than first-pregnant pregnant women. High, with statistical differences. The knowledge structure of oral health of pregnant women with different education levels and family incomes is different, and the difference is statistically significant. 
Table 2: Knowledge of oral health knowledge $n(\%)$.

\begin{tabular}{|c|c|c|c|}
\hline Knowledge of Oral Health & Yes & No & Don't Know \\
\hline Whether oral examination is needed before pregnancy & $186(60.59)$ & $85(27.96)$ & $33(10.85)$ \\
\hline Is it prone to oral diseases during pregnancy & $154(50.66)$ & $46(15.13)$ & 104(34.21) \\
\hline Whether oral diseases during pregnancy affect fetal health & $122(40.13)$ & $29(9.54)$ & $153(50.33)$ \\
\hline Whether oral treatment can be done during pregnancy & $58(19.08)$ & $143(47.04)$ & 103(33.88) \\
\hline
\end{tabular}

Table 3: Analysis of the knowledge of oral health knowledge.

\begin{tabular}{|c|c|c|c|c|c|c|c|c|c|c|c|c|}
\hline \multirow{2}{*}{ Basic Situation } & \multicolumn{3}{|c|}{$\begin{array}{c}\text { Is it Necessary Before } \\
\text { Pregnancy Have an Oral } \\
\text { Exam }\end{array}$} & \multicolumn{3}{|c|}{$\begin{array}{c}\text { Is it Easy During Pregnancy } \\
\text { Oral Disease }\end{array}$} & \multicolumn{3}{|c|}{$\begin{array}{l}\text { Oral Diseases During Preg- } \\
\text { nancy Whether It Affects } \\
\text { the Fetus }\end{array}$} & \multicolumn{3}{|c|}{$\begin{array}{l}\text { Is It Pregnant Can Do Oral } \\
\text { Treatment }\end{array}$} \\
\hline & Yes & No & $\begin{array}{l}\text { Don't } \\
\text { Know }\end{array}$ & Yes & No & $\begin{array}{l}\text { Don't } \\
\text { Know }\end{array}$ & Yes & No & $\begin{array}{l}\text { Don't } \\
\text { Know }\end{array}$ & Yes & No & Don't Know \\
\hline \multicolumn{13}{|l|}{ Age } \\
\hline$<35$ years old & 164 & 67 & 26 & 126 & 40 & 91 & 102 & 22 & 133 & 45 & 124 & 88 \\
\hline$\geq 35$ years old & 22 & 18 & 7 & 28 & 6 & 13 & 20 & 7 & 20 & 13 & 19 & 15 \\
\hline $\mathrm{X} 2$ & & 4.8219 & & & 1.7697 & & & 2.4119 & & & 2.717 & \\
\hline P value & & 0.0897 & & & 0.4128 & & & 0.2994 & & & 0.257 & \\
\hline \multicolumn{13}{|l|}{$\begin{array}{c}\text { Education } \\
\text { Level }\end{array}$} \\
\hline low & 16 & 17 & 7 & 17 & 13 & 10 & 12 & 10 & 18 & 7 & 20 & 13 \\
\hline in & 57 & 27 & 5 & 41 & 11 & 37 & 31 & 5 & 53 & 16 & 30 & 43 \\
\hline high & 113 & 41 & 21 & 96 & 22 & 57 & 79 & 14 & 82 & 35 & 93 & 47 \\
\hline $\mathrm{X} 2$ & & 6.549 & & & 6.9894 & & & 8.144 & & & 4.0171 & \\
\hline$P$ value & & 0.0378 & & & 0.0304 & & & 0.017 & & & 0.1342 & \\
\hline \multicolumn{13}{|l|}{ Pregnancy } \\
\hline For the first time & 108 & 62 & 16 & 87 & 25 & 74 & 72 & 12 & 102 & 28 & 96 & 62 \\
\hline Non-first & 78 & 23 & 17 & 67 & 21 & 30 & 50 & 17 & 51 & 30 & 47 & 41 \\
\hline $\mathrm{X} 2$ & & 7.9242 & & & 6.6626 & & & 6.9444 & & & 6.222 & \\
\hline$P$ value & & 0.019 & & & 0.0357 & & & 0.031 & & & 0.0446 & \\
\hline \multicolumn{13}{|l|}{$\begin{array}{l}\text { Household } \\
\text { Income }\end{array}$} \\
\hline low & 15 & 24 & 7 & 14 & 6 & 26 & 10 & 6 & 30 & 5 & 32 & 9 \\
\hline in & 131 & 36 & 9 & 98 & 24 & 54 & 77 & 6 & 93 & 34 & 78 & 64 \\
\hline high & 40 & 25 & 17 & 42 & 16 & 24 & 35 & 17 & 30 & 19 & 33 & 30 \\
\hline $\mathrm{X} 2$ & & 5.2382 & & & 7.4445 & & & 12.3226 & & & 8.3372 & \\
\hline$P$ value & & 0.0729 & & & 0.0242 & & & 0.0021 & & & 0.0155 & \\
\hline
\end{tabular}

\section{Oral Health Attitude Survey}

A survey of oral health-related attitudes found that about $74.34 \%$ of pregnant women were willing to participate in oral health education activities during pregnancy, 6.91\% expressed refusal, and $18.75 \%$ of pregnant women held indifferent attitudes. Regarding the question of whether or not to have a dental problem during pregnancy, $62.17 \%$ expressed their willingness and
$28.29 \%$ expressed their rejection. Influence In the survey of major factors in medicine, 58.55\% selected "Medical Quality", and those selected "Ease of Visit" 32.36\%, 9.09\% chose the "medical price".

\section{Investigation of Oral Health Behavior}

The results of the oral health care behavior survey are shown in Table 4 . Among them, more than $50 \%$ of pregnant women have not used dental floss and have never had oral examinations since 
their planned pregnancy. The situation of oral health behavior investigation and analysis is shown in Table 5 . There was no statistically significant difference in oral health care behavior between different ages. Whether the first pregnancy has no effect on dental floss, but it has an impact on the number of brushes per day, the

Table 4: Oral health behavior survey. length of brushing and oral examination. There were statistical differences in the number of brushing teeth, floss usage, and oral examination behaviors among people with different educational levels. Differences in the use of dental floss and oral examination among different household incomes were statistically significant.

\begin{tabular}{|c|c|c|}
\hline Oral Health Behavior & N & 7.89 \\
\hline 1 time & 24 & 92.11 \\
\hline$\geq 2$ times & 280 & \\
\hline Each Time You Brush Your Teeth & 263 & 13.49 \\
\hline$\leq 3 \mathrm{~min}$ & 41 & \\
\hline$>3 \mathrm{~min}$ & & 43.75 \\
\hline Use of Dental Floss & 133 & 56.25 \\
\hline Yes & 171 & \\
\hline No & & \\
\hline Have You Ever Had an Oral Examination Since Your Pregnancy? & 125 & \\
\hline Yes & 179 & 41.12 \\
\hline No & & 58.88 \\
\hline
\end{tabular}

Table 5: Investigation and analysis of oral health behaviors.

\begin{tabular}{|c|c|c|c|c|c|c|c|c|}
\hline \multirow[t]{2}{*}{ Basic Situation } & \multicolumn{2}{|c|}{ Brushing Teeth Per Day } & \multicolumn{2}{|c|}{$\begin{array}{c}\text { Each Time You Brush Your } \\
\text { Teeth }\end{array}$} & \multicolumn{2}{|c|}{ Use of Dental Floss } & \multicolumn{2}{|c|}{$\begin{array}{c}\text { From Planned Pregnancy } \\
\text { till Now Have You Ever } \\
\text { Had an Oral Examination }\end{array}$} \\
\hline & 1 time & $\geq 2$ times & $\leq 3 \mathrm{~min}$ & $>3 \mathrm{~min}$ & Yes & No & Yes & No \\
\hline \multicolumn{9}{|l|}{ Age } \\
\hline$<35$ years old & 20 & 237 & 223 & 34 & 110 & 147 & 101 & 156 \\
\hline$\geq 35$ years old & 4 & 43 & 40 & 7 & 23 & 24 & 24 & 23 \\
\hline $\mathrm{x} 2$ & \multicolumn{2}{|c|}{0.2203} & \multicolumn{2}{|c|}{0.0943} & \multicolumn{2}{|c|}{0.6076} & \multicolumn{2}{|c|}{2.2713} \\
\hline $\mathrm{P}$ value & \multicolumn{2}{|c|}{0.774} & \multicolumn{2}{|c|}{0.7588} & \multicolumn{2}{|c|}{0.4357} & \multicolumn{2}{|c|}{0.1318} \\
\hline \multicolumn{9}{|l|}{ Education Level } \\
\hline low & 6 & 34 & 32 & 8 & 15 & 25 & 7 & 33 \\
\hline In & 10 & 79 & 80 & 9 & 29 & 60 & 40 & 49 \\
\hline High & 8 & 167 & 151 & 24 & 89 & 86 & 78 & 97 \\
\hline $\mathrm{X} 2$ & \multicolumn{2}{|c|}{6.6268} & \multicolumn{2}{|c|}{0.2684} & \multicolumn{2}{|c|}{5.8285} & \multicolumn{2}{|c|}{6.3708} \\
\hline$P$ value & \multicolumn{2}{|c|}{0.01} & \multicolumn{2}{|c|}{0.6044} & \multicolumn{2}{|c|}{0.0158} & \multicolumn{2}{|c|}{0.0116} \\
\hline \multicolumn{9}{|l|}{ Pregnancy } \\
\hline For the first time & 20 & 166 & 155 & 31 & 83 & 103 & 66 & 120 \\
\hline Non-first & 4 & 114 & 108 & 10 & 50 & 68 & 59 & 59 \\
\hline $\mathrm{x} 2$ & \multicolumn{2}{|c|}{0.0109} & \multicolumn{2}{|c|}{4.1526} & \multicolumn{2}{|c|}{0.1486} & \multicolumn{2}{|c|}{6.2836} \\
\hline P value & \multicolumn{2}{|c|}{0.0273} & \multicolumn{2}{|c|}{0.0416} & \multicolumn{2}{|c|}{0.6999} & \multicolumn{2}{|c|}{0.0122} \\
\hline \multicolumn{9}{|l|}{ Household Income } \\
\hline low & 6 & 40 & 39 & 7 & 13 & 33 & 10 & 36 \\
\hline In & 14 & 162 & 157 & 19 & 80 & 96 & 78 & 98 \\
\hline High & 4 & 78 & 67 & 15 & 40 & 42 & 37 & 45 \\
\hline $\mathrm{X} 2$ & & & & & & & & \\
\hline P value & & & & & & & & \\
\hline
\end{tabular}




\section{Discussion}

Some scholars reported $[9,10]$ that the incidence of gingivitis during pregnancy in China is as high as $73.57 \%$. Pregnancy obviously promotes inflammation of periodontal tissues, and its mechanism is closely related to the gradually increasing sex hormone levels during pregnancy [11]. The plasma concentration of sex hormones during pregnancy can be up to 10 times the normal level of pregnancy, including estrogen and progesterone. Studies have confirmed the presence of estrogen receptors and progesterone receptors in periodontal tissues. Immune response, periodontal specific cells, gingival vasculature and the composition of periodontal pathogens, etc., directly or indirectly affect the progress of gingivitis [12-14]. Pregnancy gingivitis can make pregnant women feel uncomfortable during pregnancy and may lead to adverse pregnancy outcomes [4]. Therefore, pregnant women should pay attention to prevent the occurrence of pregnancy gingivitis. China's Yang Xiuqiao and others [15] found that some pregnant women have obvious deficiencies in the understanding and behavior of pregnancy gingivitis. Therefore, it is of great significance to fully understand the degree of pregnant women's knowledge of oral health, related attitudes and behavioral status, Conducive to targeted oral health education and behavior guidance for pregnant women. This study selected 304 pregnant women in the obstetrics outpatient clinic of the Shenzhen Maternal and Child Health Hospital in Guangdong Province in China to conduct a questionnaire survey. The results showed that $60.59 \%$ of pregnant women agreed to need oral examination before pregnancy; $49.34 \%$ of pregnant women did not agree or did not know that oral cavity was easy to occur after pregnancy Diseases; $59.87 \%$ of pregnant women believe that oral diseases during pregnancy have no effect on fetal health or do not know; $47.04 \%$ of pregnant women believe that oral treatment is not allowed during pregnancy; at least more than a quarter of pregnant women have a negative attitude towards oral health; only $13.49 \%$ of pregnant women spend more than 3 minutes each time brushing their teeth, $56.25 \%$ of pregnant women never use dental floss, and 58.88\% of pregnant women have never had an oral examination since their planned pregnancy. Among them, nearly half or more than half of the pregnant women have the possibility of oral diseases after pregnancy, whether oral diseases during pregnancy have an impact on fetal health, whether oral treatment can be done during pregnancy, the length of each brushing and the use of dental floss. Wrong knowledge, attitude and behavior. Bamanikar et al. [16] found that $96.8 \%$ of pregnant women in Brunei agreed that oral examinations were required during pregnancy, $55.9 \%$ of pregnant women had undergone oral examinations from planned pregnancy to date, and $40.9 \%$ of pregnant women used dental floss every day. Compared with the results of this study, it shows a large gap.

Pregnant women are related to the knowledge, belief and practice of oral health care. Because $49.34 \%$ of pregnant women do not agree or do not know that oral diseases are prone to occur after pregnancy, and $59.87 \%$ of pregnant women think that oral diseases during pregnancy have no effect on the health of the fetus or do not know, so $47.07 \%$ of pregnant women think that oral cavity can not be done during pregnancy After treatment, 86.51\% of pregnant women brushed their teeth less than 3 minutes each time. That is, a bad "faith" is caused from a bad "knowledge", resulting in a bad "line". Chawla et al. [17] found that there is a big difference between pregnant women's knowledge and behavior. Specifically, although a considerable number of pregnant women have correct oral health knowledge, their oral health behavior is very unsatisfactory. The results of this study found that pregnancy times, education and family income all have an impact on pregnant women's oral health knowledge and behavior. The higher the education level of pregnant women and the higher the family income, the more accurate oral health knowledge they have. Have more correct oral health behaviors. China's Yang Xiuqiao [14] and other 380 pregnant women found that highly educated pregnant women brush their teeth $\geq 2$ times a day, and the proportion of teeth cleaned before pregnancy is significantly higher than that of low-educated pregnant women, indicating that high-educated pregnant women have a strong awareness of oral health, namely Pregnant women with a high degree of education may have better "knowledge" and thus a better "walk".

Consistent with the results of this study. In addition, Llena et al. [18] believed that low-income pregnant women had less oral knowledge and had a higher misunderstanding of oral treatment, and worried that oral treatment would affect the fetus, so they adopted an attitude of avoiding medical treatment, that is, low-income pregnant women may have poorer The "knowledge" of the word appears to be worse. The above direct and indirect evidences indicate that the current knowledge and behavior of pregnant women in oral health may have different results due to regional or population differences. Overall, there are significant deficiencies. Studies have shown that [17] oral intensive education during pregnancy can greatly improve the knowledge and attitude of oral health during pregnancy and improve oral health. It shows that oral health education plays an important role in maintaining oral health and improving oral health awareness. Oral health education during pregnancy is not only beneficial for maintaining the oral condition of pregnant women themselves, but also for the oral health of their children. This study has certain limitations because it is a questionnaire survey study. Due to the limited sources of pregnant women surveyed, the results of this study only represent the knowledge, practice and behavior of oral health of pregnant women in a region, so they are only for reference in interpretation.

\section{Foundation}

Supported by Maternal and Child Healthcare Center, Chinese Center for Disease Control and Prevention (Grant Number: 2018FYH013).

\section{References}

1. Iida H (2017) Oral health interventions during pregnancy. Dent Clin North Am 61(3): 467-481. 
2. Hartnett E, Haber J, Krainovich-Miller B, Bella A, Vasilyeva A, et al. (2016) Oral health in pregnancy. J Obstet Gynecol Neonatal Nurs 45(4): 565-573.

3. George A, Johnson M, Reath J, Bhole S, Ajwani S, et al. (2013) Oral health care during pregnancy. Aust Nurs Midwifery J 21(3): 42.

4. Jain K, Kaur H (2015) Prevalence of oral lesions and measurement of salivary $\mathrm{pH}$ in the different trimesters of pregnancy. Singapore Med J 56(1): 53-57.

5. Offenbacher S, Katz VL, Fertik GS, J Collins, D Boyd, et al. (1996) Periodontal Infection as a possible risk factor for preterm low birth weight. J Periodontol 67(10 Suppl): $1103-1113$.

6. Holt KA (2012) Oral health care during pregnancy: A national consensus statement. 140st APHA Annual Meeting and Exposition.

7. Wu Yafei (2017) Interpretation of consensuses on treatment of female patients with periodontal disease. Chin J Stomatol 52(2): 75-76.

8. World Health Organization (2013) Oral Health Survey Basic Methods. In: (5 ${ }^{\text {th }}$ Edn), WHO, Geneva, pp. 20-33.

9. Wu Xinyu, Cai Qiaoyi, Zhou Yikun (2017) Clinical parameters and risk factors of pregnancy gingivitis. Int J Stomatol 44(2): 200-203.

10. Huanxin M (2017) Clinical Periodontology. In: ( $2^{\text {th }}$ Edn), Beijing Medical University Press, China.

11. McKnight H, Kelsey WP, Hooper DA, Hart TC, Mariotti A, et al. (2014) Proteomic analyses of human gingival and periodontal ligament fibroblasts. J Periodontal 85(6): 810-818.
12. Yokoyama M, Hinode D, Yoshioka M, Fukui M, Tanabe S, et al. (2008) Relationship between Campylobacter rectus and periodontal status during pregnancy. Oral Microbiol Immunol 23(1): 55-59.

13. Usin MM, Tabares SM, Parodi RJ, Sembaj A (2013) Periodontal conditions during the pregnancy associated with periodontal pathogens. J Investig Clin Dent 4(1): 54-59.

14. Hartnett E, Haber J, Krainovich-Miller B (2016) Relationships between periodontal health, salivary steroids, and Bacteroides intermedius in males, pregnant and non-pregnant women. J Obstet Gynecol Neonatal Nurs 45(1): 565-573.

15. Xiuqiao Y, Chanjuan Y, Min W (2019) Evaluation of periodontal status of 380 pregnant women and analysis of the related factors. J Pract Stomatol 35(1): 109-113.

16. Bamanikar S, Kee LK (2013) Knowledge, Attitude and Practice of Oral and Practice of Oral and Dental Healthcare in Pregnent Women. Oman Med J 28(4): 288-291.

17. Chawla RM, Shetiya SH, Agarwal DR, Mitra P, Bombl NA, et al. (2017) Knowledge, attitude and practice of pregnant women regarding oral health status and treatment needs following oral health education in Pune district of Maharashtra: A longitudinal hospital-based study. J Contemp Dent Pract 18(5): 371-377.

18. Llena C, Nakdali T, Sanz JL (2019) Oral Health Knowledge and Related Factors among Pregnant Women Attending to a Primary Care Center in Spain. Int J Environ Res Public Health 16(24): 5049.

\section{Your next submission with Juniper Publishers} will reach you the below assets

- Quality Editorial service

- Swift Peer Review

- Reprints availability

- E-prints Service

- Manuscript Podcast for convenient understanding

- Global attainment for your research

- Manuscript accessibility in different formats

( Pdf, E-pub, Full Tsext, Audio)

- Unceasing customer service

Track the below URL for one-step submission

https://juniperpublishers.com/online-submission.php 